\title{
Swimming Learning Model Using Rope As Aid For Beginners
}

\author{
Meirizal Usra \\ Sriwijaya University \\ Palembang, Indonesia \\ meirizalus@gmail.com
}

\begin{abstract}
Swimming is a sport much favored by many and one needs to have the courage to be able to swim. In swimming lessons in schools, there are still many students who are afraid to swim for fear of drowning and other reasons. The key to being able to swim is being able to float. When one can float, he or she can easily make any swimming movements. Based on observations, a lot of kids want to try to swimming but are hampered by several obstacles, such as fear of drowning and so forth. This makes a child unwilling to swim. This also happens to students who attend classes on swimming pools. Out of the total 82 students in this class, 23 students could not swim and are afraid to carry out activities such as gliding, dipping heads and diving in shallow areas. Based on this background, the research problems are: Is the form of learning to swim using the rope as aid can improve a beginner's ability to swim? The purpose of this research is to improve the learning ability to swim through a learning model using the rope as aid. Based on the results of research and discussion, we can conclude that there is an improvement in the swimming learning process with the help of a rope. Improvement in the learning through the method of swimming with the rope as an aid to the students of the State University of Sriwijaya, Palembang can be seen from their improved learning process and participation. There is a significant improvement in the outcomes in the three learning cycles that have been prepared, namely cycle one, by which the students apply the learning method of floating with rope as aid; cycle two, by the method in which they swim using rope as aid, and cycle three, the method in which they make swimming motions freely without any aid. Change occurs in the application of the swimming method of using the rope as the aid in which students who initially could not swim can eventually swim.
\end{abstract}

\section{Keywords—swimming learning; help rope}

\section{INTRODUCTION}

\section{A. Background}

Sports swimming is a sport that is very much in demand by children, youth, parents, and the elderly. To be able to be swimming in need courage, as well as an outdoor learning in schools are still many children who are afraid to swim because the fear of drowning and others because the primary key can swim that float when it is able to float someone will easily make swimming movements. During this time learning to float a lot done in a shallow pool is causing a child needs a long time to be able to float in its own way

Swimming requires courage, but for beginners, it is extremely difficult in practice, due to a lack of confidence in doing so. The cause of fear arises because of the lack of area to play in the water, another factor is never experienced unpleasant circumstances such as choking or drowning even when swimming up to the nose of the incoming water. To overcome all these fears, need a method of teaching that bias overcoming these problems. The importance of tools for instilling confidence is the main thing in the learning process. Tools can instill the confidence to try swimming.

This is due to the lack of area to play in the water, another factor is never experienced anything unpleasant as choking or even drowning while swimming up to his nose much penetration of water. To overcome all these fears problems required a gradual habituation way. Against this problem is done by initially let the kids just soak her feet or splashing in the pool toys while still wearing a bathing suit. It could also put children into the swimming club handled masterfully. Or often took a swim together with relatives/friends of his age. Of course, while continuing accompanied and built his confidence that the swim was fun, so do not be afraid. This method is often done by many people or experts. The introduction of the water as early preparation for learning to swim is a thing that should be done to those who want to learn swimming that aims to prepare themselves physically and mentally.

Based on the above research must be done in an attempt to get outdoor teaching methods with the help of a rope for beginner swimmers. In relation to the description described, the authors will carry out research on Improving Learning Pool with Help Rope for Beginner Swimmers.

\section{B. Problem Formulation}

Formulation of the problem based on this background is: Is a form of learning with the help of ropes pool can enhance the ability of swimming for swimmers' beginners?

\section{Objective}

The purpose of this research is to improve the learning ability of the swimming pool through a learning model with the help of a rope.

\section{Benefits Research}

The benefits of this researchers are as follows:

- Beneficial for Lecturer / Assistant swimming pool learning process. 
- Helpful for swimming instructors in fostering a novice swimmer.

- As a first step for the development and improvement of the swimming lesson.

\section{Swimming}

1) Nature of Swimming: Swimming a physical activity carried out in water by using a limb or part of a limb. Someone with movements of the body in the water to be moved around the place is said to swim. The activity of using body swimming, float across water using hands and feet. Swimming style is motions made at the championship race in the swimming pool. Swimming styles competed in swimming championships include styles as follows; style crawl or freestyle, the style of back crawl or backstroke, breaststroke or breaststroke style, butterfly style or a butterfly. Swimming with these forces can do when they are taught first through stages exclusively in teaching methodology swim. Swimming stage in the study include the introduction of water and the basics of swimming. Human beings, in principle, not the water that needs their physical and psychological preparation to face the activity on the water. This is in contrast to the fish as animals that live in water. The introduction of water as a prelude to preparation for learning to swim is a matter that must be done. The introduction of this water to those willing to learn to prepare physically and mentally pool. Explains that it is physical to be prepared to get to know the properties of water, namely; water will wet the body, moving in the water become a bottleneck, there needs to be a balance move in the water, the water is transparent, it is necessary to understand the depths.

2) Miscellaneous The Style Swimming Pool: Swimming consists of four styles, namely:

- Freestyle

- Breaststroke

- Backstroke

- Style Butterfly

3) Nature of Learning: Ways to give swimming lessons are well known such as 1) Lesson swims ashore is a way in which the movements gave first pool outside pool (cleaning in place) with a stand or lie on the floor. 2) Lessons swimming with assistive devices, there are two ways: (a) Using a rod (Hengelmethode). After a lesson on land was completed in general began lessons with assistive devices such as fishing. (B) Using the tools of the float. Tool-tool used for the float is in the form of boards, a tin filled with air, the wings filled with air, cork. 3) a reasonable method (Naturlicher Schwimmunterricht), are swimming lessons where the whole movement, motion naturally, tailored to the child and given in the form of games [1]. Ref. [2] states that novice swimmers should first of all be taught to float, because the most difficult swimming style consists of only two basic: First, floats and, second, adding the swing push to make the body move from one place to another.

\section{4) Benefits of Swimming:}

a) Improve Brain Capability: Regular physical exercise can improve concentration, creativity, and mental health. Because exercise can increase the amount of oxygen in the blood and accelerate the flow of blood to the brain. Experts believe that these things can encourage physical and mental reactions better. Results of studies have been published on the Proceedings of the National Academy of Science, said that the benefits of proper and regular exercise can stimulate the growth of neurons (nerve cells) that have been damaged.

b) Helps delay the aging process: Research shows that a simple exercise such as swimming regularly can help reduce mental decline in women over 65 years. The more often and the longer they do so than the mental decline more slowly. Reportedly, many people feel the benefits of the activity after nine weeks of doing it regularly three times a week. This exercise should not be done at a high intensity. Quite a breath floats and making repeated.

c) Reduce Stress: Exercise can reduce anxiety. Even further, can help control anger. Aerobic exercise can increase the ability of the heart and make the body more quickly to cope with stress. Activities such as walking, swimming, cycling, and running are the best way to reduce stress.

d) Increase endurance: Glad to exercise but not too long, frequent or prolonged, but with a relaxed do it, then that activity can increase good hormones in the brain such as adrenaline, serotonin, dopamine, and this endorfin. Hormon role in increasing endurance. Studies conducted in showed that 83 percent of people who have mental disorders rely on exercise to improve mood and reduce anxiety. While researchers at Duke University found that 60 percent of depressed people who do sports for four months with a frequency of three times a week, and each exercise for 30 minutes can overcome these symptoms without medication. Although classified as efficacious measures but it does not mean that treatment can be stopped immediately, especially for those who are severely depressed.

Generally, the more proficient person in a particular type of activity, then the confidence will increase. Even a study proves that teens who actively exercise feel more confident than her friends who do not carry out similar activities.

5) Learning Tools:

a) Understanding Learning Tools: Tools are the tools used by educators in delivering learning materials. This tool is more commonly referred to as props because it serves to help and practice learning something in the process.Tools intended for exerting the senses as much as possible an object to facilitate a perception. The benefits of learning in detail as follows: 1) Generate interest in the education target, 2) Achieve goals more, 3) To help overcome language barriers, 4) Stimulate educational goals carry health messages, 5) Assist educational goals to learn more and faster, 6) Stimulating educational goals for Forward messages acceptable to others, 7) Facilitate the delivery of educational materials / information by the educators educational actors.

b) Terms of Learning Tools are Good: Teaching aids said well if it has the purpose of education to change the knowledge, 
understanding, opinions, and concepts, changing attitudes and perceptions, instill behavior / new habits. Tools must be efficient in its use, in a short time can include extensive content. Tools for effective learning means giving a high effectiveness in terms of its message and the interests of students who are learning. Communicative tools are that these tools are easy to understand the point, so as to make students become easier to accept the teaching given by the teacher.

\section{METHODS}

\section{A. Methods}

The method used in this research is a classroom action research with experimental types namely classroom action research conducted by attempting to apply different techniques and models to effectively and efficiently in a teaching and learning. In the relation to the teaching and learning activities is possible there is more than one model to achieve instructional goals, with the implementation of action research is expected that researchers can determine which is the more effective manner in order to achieve the goal of teaching.

\section{B. Subject Research}

The subjects of this study were students Physical Education of Sriwijaya University semester 2016/17 year. A number of subjects in the study of 23 people consisting of 14 males and 9 female students.

\section{Place and Time Research}

Research conducted at the Lumban Tirta Swimming Pool Palembang and Swimming Pool Jakabaring. It determines the pool is based on lectures. The timing of the months of June 1 until September 2016.

This research activity includes the preparation, execution, and preparation of reports. Preparation activities include observation, problem identification, determination of the action, filing title, proposal development and submission of research permits. The activities include the implementation of the proposals and the collection of research data. Preparation of the report includes report writing.

\section{Procedures for Research}

Research implementation of class action procedures implemented in the form of 3 (three) cycles. Implementation of each cycle designed to improve learning if one cycle has yet to show signs of problem-solving toward improvement (increase), research activities continued on the second cycle, and so on, aspects are observed in each cycle is an activity during the learning pool with learning model application swim with help of a rope. This study is a class action so that researchers always cooperated with swimming Lecturer, starting from the beginning of the dialogue, action planning, action, observation or monitoring (observation), reflection (reflection) on every action and evaluation. Here's an explanation of each of these steps in action research activities:

1) Early Dialogue: the Initial dialogue was conducted to determine the extent of the root causes which consists of the learning underway include outdoor learning outcomes in learning.
2) Planning: This stage in the form of drafting action explain the what, why, when, where, by whom and how it was committed. In the planning stage researchers to determine the focus of events that need special attention to be observed, then make observation instruments to record the fact that occur during these procedures. Measures for solving the problem which is preparing an action plan, including revisions and changes to the plan was to be done in a swimming lesson. In regard to plans drawn up collaboratively between researchers and lecturers swimming mastery. It carried out at this stage are: 1) Determine the class of subjects to be studied, ie PE Students. 2) Setting the number of cycles, which is 3 cycles. 3) Set up a method of teaching based on learning models for this type of cycle, namely in the form of lectures, demonstrations, discussion and question, and answer. 4) Prepare lesson plans that will be applied every cycle. 5) Set up a learning resource. 6) Determine the observer and the observer tools. 7) Establish how the implementation of reflection and reflection researcher. 8) Establish criteria for success in efforts to solve the problem.

3) Action: At this stage, the draft strategy and implementation scenarios of learning will be applied. The design of these actions has been "trained" to the implementing measures (Lecturer) to be applied in the classroom according to the scenario. The scenario of the action to be well and seemed reasonable. Details of the actions performed are: 1) Taking a breather in the water with the body using a rope binding safeguards aimed at administration, 2) Floats/floating in the water with the body prone position tied with ropes for security, 3) The movement of the feet on the bottom that leads to freestyle.

4) Observations: In the observation phase is observed: 1) Technical breath-taking, 2) Position of float movement, 3) The direction of movement of the foot.

5) Reflection: Results were analyzed showed there are not achieving the criteria bold in swimming and can carry out the instructions properly. This activity then resumed cycling 2 and 3.

\section{E. Data Sources}

Data and data sources of the study include the type of data and data sources. The type of data this study is to float and swim with the help of a rope. The data used in this study are as follows: 1. Students as subjects to obtain data about the activity of swimming ability. 2. Lecturer as a collaborator, to see the level of success of the application of learning to use tools rope. 3 . The results of formative tests in the form of quantitative data. 4. The observation of student activity in the form of qualitative data.

\section{F. Research Schedule}

This activity was carried out in April 2016 until September 2016 with details of the activities of the filing of the proposal, selection of proposals, implementation research, evaluation and research reports 


\section{RESULT AND DISCUSSION}

\section{A. Process Reseach}

Research carried out on the pool action Lumban Tirta Swimming Pool Jakabaring Palembang and recline. Researchers observe the learning process in an effort to increase learning swimming pool through the help of a rope, which was conducted in two cycles. The learning process in each cycle carried out in (1) meetings.

1) Cycle One:

a) Stage Planning (planning): The planning phase, researchers plan learning scenarios and also set up support facilities to carry out the action scenarios. In detail the activities carried out in the planning stage are 1) Create a learning model scenarios with the help of ropes pool, 2) Setting up learning facilities, swimming pools, equipment for swimming teaching model with the help of a rope. 3) In this study, and structured instrument for monitoring the implementation of the model with the help of ropes pool. 4). Determine the technical implementation of the study. 5) Set up the reflection.

b) Implementation phase (action): The learning process of the cycle, held on Monday, June 6, 2016, effective two-hour lesson (100 minutes), with the sequence of events as follows: 1) Lecturers and students departed from the State University of Sriwijaya, headed to the pool Lumban Tirta, as the location for the conduct of research. 2) Lecturer collect student at the pool with aligned manner, one of the children asked to lead the prayer, lecturer roll student, in this case, the number of students 42 incoming all and that cannot be swimming as much as 23 . Furthermore convey information including the following: the student needs to know that starting today Monday, June 6, 2016, until Friday 24 June 2016 schedule is subject learning materials swimming pool with the help of a rope. students are encouraged to participate in an outdoor learning with the help of a rope with the best. 3) At this stage in the cycle of learning this one, researchers conducted in accordance learning the lesson plans have been developed and validated in the planning stages. Action in the learning process in one cycle is done in one learning process. Swimming learning materials with the help of a rope that will be tested in one cycle of this meeting in the form of floats with the help of a rope. 4) The material presented in the meeting of the learning cycle with the help of a rope is swimming; float with the help of a rope, 5) swimming lesson with the help of a rope on the learning process of faculty and students, conducted by lecturers, which was conducted using observation

c) Observations: The results of observations made by the two collaborators, the result: Development of Students. Observations about student participation in a single cycle, the results obtained in the initial student who cannot swim after being awarded a swimming lesson with the help of a rope so the student can float even though there are still afraid.

d) Reflection: The results reflect the learning activities in the cycle of the show, that: 1) The learning process lecturers. Activities are quite capable of learning faculty encourage students' creativity to move during the learning takes place. The learning model used by faculty, in accordance with the teaching materials. 2) The Students actively participate in the pool following the learning process with the help of a rope. The creativity of students to be active during the learning is maximal. Some students seem less able to complete the tasks assigned faculty quite well. Thus we concluded that the already visible increase in swimming lesson with the help of a rope that is significant in this one cycle activities. Some students were not able to do motion float properly so that the learning outcomes cannot be achieved to the maximum. It required the design of learning in the next cycle (cycle two) based on the results of this one cycle of reflection, to enhance learning with the help of ropes pool properly so that the objectives and learning outcomes can be achieved. As well as efforts to further enhance the activity and skills of students and create a more pleasant learning activities.

2) Cycle Two: Cycle two learning activities held on Monday, June 13, 2016, with an allocation of 2 hours lesson time effectively (100 minutes). From the result of reflection on learning activities cycle one taken at issue, namely: the learning process lecturer has a maximum, students can perform motion float even though it appears some students still missing, it still needs to be improved further learning basic motion swimming with the approach of the pool with the help of a rope. The sequence of learning activities in two cycles are as follows:

a) Plan: Based on the result of reflection on the cycle of learning activities, it is designed action on two cycles to improve future learning. The results reflect a cycle of learning activities has shown an increase the effectiveness learning, so that the two cycles of learning activities as the development of learning that has taken place in a single cycle. After finding flaws in the cycle to one, that not all students can perform to the maximum floating motion, and efforts should be made so that the learning is increased, then the next Researchers create learning design for implementation in two cycles.

b) Implementation measures: 1) In this second cycle, the researchers carry out appropriate learning lesson plans that had been developed and validated in the planning stages. Actions in these two cycles in a single learning process. 2) swimming learning materials with the help of a rope that will be tested in two cycles is more directed to perform motion activities freestyle but still with the help of a rope. 3) The material presented in the meeting of two learning cycles with the help of ropes pool is: Doing freestyle movement but still with the help of a rope. 4) swimming lesson with the help of a rope on the learning process of faculty and students, conducted by lecturers, which was conducted using the observation sheet.

c) Conclusion Observations: The results of the observation sheet researchers note indicates that students are already well on actively participate. Almost all the students move movement and participate actively swimming in the pool. Almost all students can complete a given task with a good lecturer. In addition, the learning atmosphere is pleasant, this is evidenced by all the students excited about learning, serious in following the learning process and all the students are responsible for carrying out the task of lecturers. 
d) Reflection: The results reflect the learning activities in two cycles show that: 1) Lecturer Learning Process. The learning process with the help of ropes pool presented by the lecturers has been able to encourage the creativity of students to be active during learning. Lecturer able to increase student motivation in participating in learning activities. Usage models of rope help assistance in accordance with the teaching materials. 2) Participation of students Their active participation and creativity of the students in the learning core activities. When closing activity there are some students who are asking the question, "Sir, when swimming again without the help of a rope?", Almost all the students seemed glad for the learning and all students can do and follow the pool with a good learning. We concluded that the already visible increase in swimming learning through the help of a rope at a meeting in two cycles. The results of this study in two cycles, the learning process has been running optimally lecturers, students can perform and follow with good swimming lesson, the students stated that learning fun, liveliness and swimming abilities of students have appeared, so that the learning objectives have been achieved.

3) Cycle Three: Cycle three learning activities held on Monday, June 20, 2016, with an allocation of 2 hours lesson time effectively (100 minutes). From the result of reflection on learning activities cycles one and two were taken at issue, namely: the learning process lecturer has a maximum, students can perform motion float and swim with the auxiliary ropes, but the latter process that students are able to do the activity swimming on its own, then it still needs to be improved basic motion learning processes swimming pool approach with the help of a rope. The sequence of learning activities in three cycles are as follows:

a) Plan: Based on the result of reflection on learning activities cycles one and two, then designed action on three cycles to improve future learning. The results reflect the learning activity cycles one and two already showed an increased the effectiveness of the learning, so that the three cycles of learning activities as the development of learning that has taken place in cycles one and two. After finding flaws in cycle one and two, that not all students can do without the help of a rope swimming motion to the fullest, and efforts should be made so that the learning is increased, then the next Researchers create learning design for implementation in three cycles.

b) Implementation measures: 1) In this second cycle, the researchers carry out learning in a program that had been developed and validated in the planning stages. Action in three cycles are done in two times the learning process, 2) swimming learning materials with the help of a rope that will be tested in three cycles is more directed to perform activities freestyle swimming motion without the aid of a rope or doing their own swimming. 3) The material presented in the meeting of two learning cycles with the help of ropes pool is: Doing freestyle movement without the help of a rope. 4) without the aid of ropes pool learning about the learning process of faculty and students, conducted by lecturers, which was conducted using the observation sheet. c) Conclusion Observations: The results of the observation by the researchers note sheet shows that students are already well on actively participate. Almost all the students move movement and participate actively swimming in the pool. Almost all students can complete a given task with a good lecturer. In addition, the learning atmosphere is pleasant, this is evidenced by all the students excited about learning, serious in following the learning process and all the students are responsible for carrying out the task of lecturers.

d) Reflection: The results reflect the learning activities in three cycles show that: 1) Learning Process. The learning process with the help of ropes swimming presented by the lecturers has been able to encourage the creativity of students to be active during learning. Lecturer able to increase student motivation in participating in learning activities. The use of models in accordance with the ropes help of teaching materials.2) Participation of students. Their active participation and creativity of the students in the learning core activities. Almost all the students seemed glad for the learning and all students can do and follow the pool with a good learning We concluded that the already visible increase in swimming learning through the help of a rope at a meeting in three cycles. The results of this study in three cycles, the learning process has been running optimally lecturers, students can perform and follow with good swimming lesson, the students stated that learning fun, liveliness and swimming abilities of students have appeared, so that the learning objectives have been achieved.

\section{B. Discussion}

The results showed that there was an increase in the learning process, from opening until closing motion learning basic swimming pool with learning methods with the help of a rope. As evidenced by the significant increase in the learning process during their treatment in the activities of the learning process in three cycles. Looks lecturers able to motivate students in participating in learning activities to swim with help of a rope. Lecturers are able to manage the class well, so that learning activities can be controlled and faculty was able to create an atmosphere of learning activities for students who are fun, so students enthusiastic in participating in the learning process with the help of rope swimming.

There enhancement that significant of the third cycle that has been collated in such a way, from the cycle of a given method of learning to float with the help of a rope, the cycle into two, namely learning methods swimming with the help of a rope, and a cycle of three that students perform swimming movements by itself without aided by a rope. The amendment is of that cannot be given the pool after swimming learning method with help of rope, students who cannot swim in the end could swim

In addition, the results of this study also showed significant increase of the third cycle that has been collated in such a way, from the cycle of a given method of learning to float with the help of a rope, the cycle into two, namely learning methods swimming with the help of a rope, and a cycle of three that student movement in the pool by themselves without help with a rope. The amendment is of that cannot be given the pool after 
swimming learning method with rope, students who cannot swim in the end could swim.

\section{CONCLUSIONS}

\section{A. Conclusions}

Based on the results of research and discussion, we can conclude that there is an increase in the learning process with the help of ropes pool. Improved learning through learning methods swimming pool with the help of ropes State University student Sriwijaya, can be seen from the increase in the learning process and increase student participation. Learning outcomes there significant increase of the third cycle that has been collated in such a way, from the cycle of a given method of learning to float with the help of a rope, the cycle into two, namely learning methods swimming with the help of a rope, and a cycle of three that students do swimming motions with The aid itself without a leash. The amendment is of that cannot be given the pool after swimming learning method with help of rope, students who cannot swim in the end could swim.

\section{B. Suggestions}

Based on the conclusion, suggestions can be submitted include 1. The approach of learning through teaching methods with the help of ropes pool needs to be cultivated for more learning, so researchers are more interested in developing their creativity to create innovation in the delivery of learning. 2. civilizing physical activity students need support from various parties, including the elderly, education providers. 3. Expected learning methods with the help of ropes pool can be applied to universities throughout Indonesia.

\section{REFERENCES}

[1] O. Sioe Tjiang and S. Taringan, Renang, Jakarta: Keng Po, 1962.

[2] T. David G, Renang Tingkat Pemula, Jakarta Utara: PT Raja Grafinso Persada, 1996. 